\title{
Analysis of chemical volume and composition to overcome liquid loading in gas well
}

\author{
Abdul Wahid ${ }^{1, *}$, and Muhamad Taufiq Hidayat $^{1}$ \\ ${ }^{1}$ Department of Chemical Engineering, Faculty of Engineering Universitas Indonesia, Kampus Baru UI, Depok 16424 Indonesia
}

\begin{abstract}
Many problems often occur in producing natural gas from well. Due to the existence of water content in natural gas or water drive mechanism, liquid (especially water) is also produced from gas well, following natural gas production. When gas critical rate is higher than gas production rate due to reservoir pressure decline, it will cause liquid accumulation in the bottom of well, avoiding natural gas to be well lifted from well bottom to surface. It is liquid loading. Chemical injection of 0.4 liquid that consists of ethoxy sulphate, alkane sulphonate, and petroleum sulphonate is effective to overcome liquid loading in natural gas well thus causing an increase in natural gas production by $57 \%$.
\end{abstract}

\section{Introduction}

The imbalance between natural gas production and its demand causes Indonesia to become a natural gas net importer country by 2025 [1]. Many factors cause low natural gas supply, including operational problem in gas well that decreases gas production. There are four main operational problems in natural gas production : low productivity, excessive water production, sand production from sandstone reservoir, and liquid loading [2]. In natural gas production from well that consists of high water content gas or gas reservoir with water drive mechanism, water is routinely produced with natural gas. With reservoir decline due to natural gas production, water is accumulated in the bottom of well and causes liquid loading. It decreases gas rate production as shown by Figure $1[3,4]$.

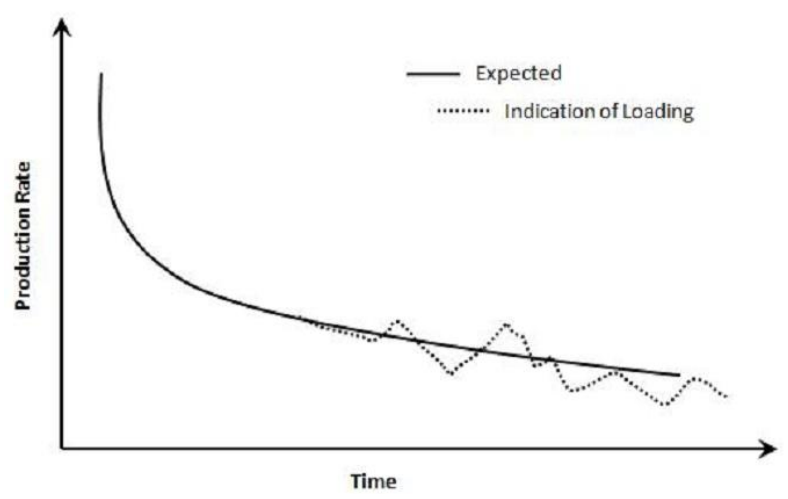

Fig. 1. A Typical Gas Well Decline Curve along with Indication of Loading [4]

Chemical injection which consists of ethoxy sulphate, alkane sulphonate, and petroleum sulphonate is used to overcome liquid loading in natural gas well. Capillary string that has smaller inner diameter than production tubing diameter is installed to flow chemical mixture to well bottom. Theoretically, small inner diameter tubing is easier to lift gas from bottom part to surface [5]. With appropriate composistion of injected chemical, liquid loading can be overcome and gas production rate increases.

\section{Water Gas Ratio}

The occurence of liquid loading in well bottom is related to gas critical rate. Reservoir pressure decline due to natural gas production will decrease gas rate production. If it is lower than gas critical rate, the minimum gas rate to lift gas from well bottom to surface, liquid loading tends to occur in well bottom. Liquid, especially water, is produced following natural gas production. Water gas ratio (WGR) is simulated by using software to analyse the amount of water production with gas. WGR is related to the reservoir properties, especially pressure and temperature.

Figure 2 is water gas ratio in $\mathrm{X}$ well as a case study, shows the amount of water production in particular natural gas production unit that is simulated in various reservoir pressure and temperature. $\mathrm{X}$ well is produced from reservoir with 730 psia pressure and $176^{\circ} \mathrm{F}$ temperature. In Figure 2, it is shown in line 7. By ploting reservoir pressure and temperature, water gas ratio in $\mathrm{X}$ well is analysed. The $\mathrm{X}$ well water gas ratio is 1.4 $\mathrm{Stb} / \mathrm{MMscf}$. It can be infered that in every $1 \mathrm{MMscf}$ production of natural gas, 1.4 Stb of water is produced.

Coresponding author : wahid@che.ui.ac.id 

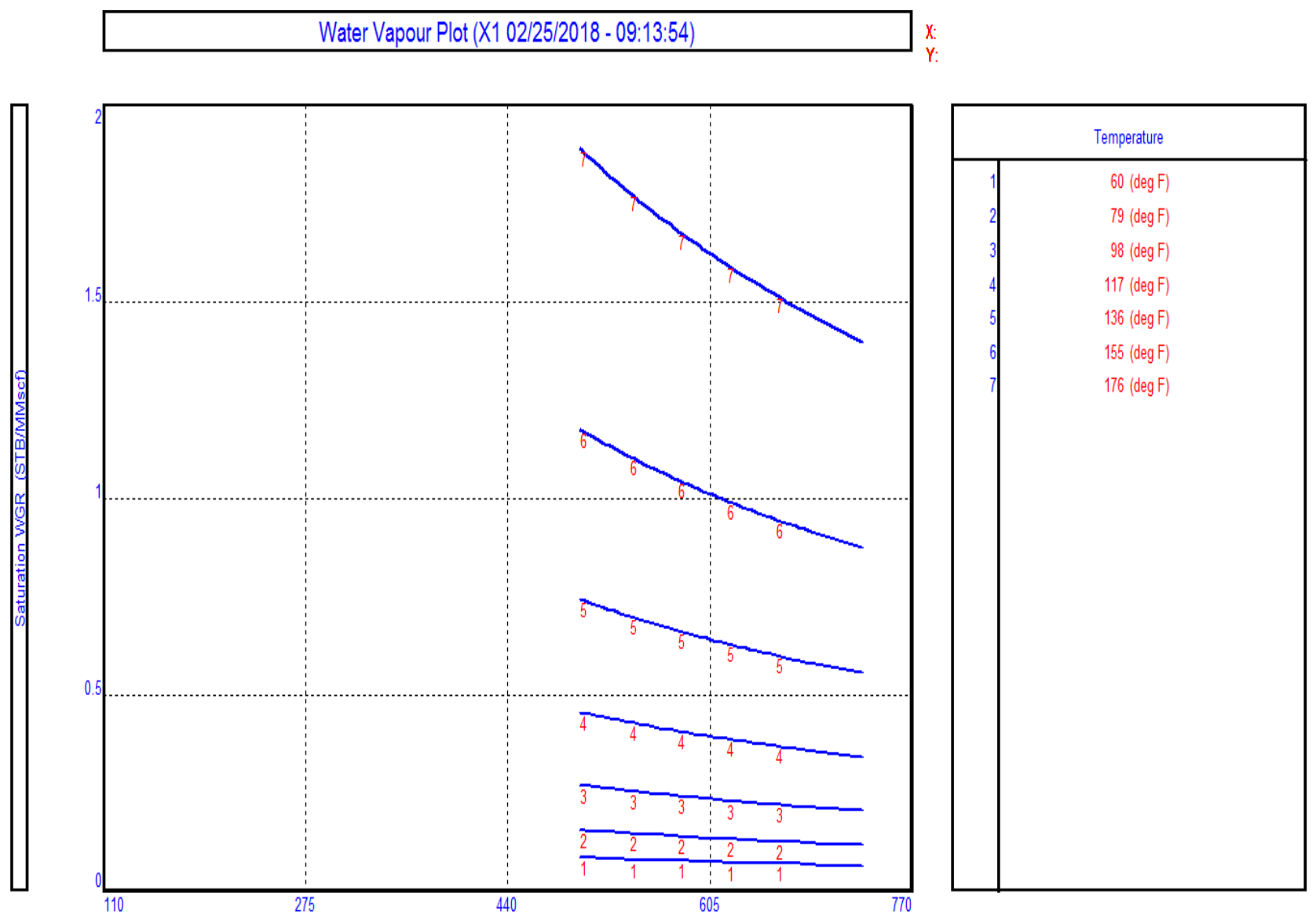

Pressure (psig)

Fig. 2. Water Gas Ratio

This condition creates liquid loading occurence in $\mathrm{X}$ well. Phase envelope is also simulated to support this analysis. From software simulation to figure phase envelope of $\mathrm{X}$ well, the cricondentherm and crocondenbar is $49^{\circ} \mathrm{F}$ and $1,535 \mathrm{psig}$ respectively. Since the pressure is higher than atmospheric pressure and the temperature is lower than atmospheric temperature, produced natural gas from $\mathrm{X}$ well is remain in gas phase in the atmospheric pressure and temperature. Simply, natural gas production from $\mathrm{X}$ well is originally from gas cap reservoir.

The water gas ratio and phase envelope simulation result indicates that water production, that is then accumulated in well bottom, is not come from water content in natural gas but from formation water. Produced water flows from water formation following natural gas production. This condition is often occurs in natural gas production process with declined reservoir pressure.

The indication of liquid loading that occurs in well bottom can be checked in well surface. It can be directly indicated and measured to finally infered the occurence of liquid loading in natural gas well with some of the following indicators :

- liquid slug in surface,

- increase of pressure difference between tubing and casing,

- the excessive change of flow gradient,

- the excessive decline of gas production,

- unstable pressure measurement in orifice,

- the fluctuative gas production rate.

Liquid slug in well surface indicates the occurence of liquid loading in well bottom and is supported with the measurement result of tubing and casing pressure. The increase of pressure difference between tubing and casing indicates the occurence of liquid in natural gas well. It is related to the influence of water accumulation to tubing pressure. Beside that, the fluctuative of natural gas production data indicates the occurence of liquid loading in well bottom.

The flow of natural gas from well bottom to surface is affected by gravity. Due to that, gas production rate is keep higher than critical rate to avoid water accumulation in well bottom. Lower gas rate than critical rate causes water drops to well bottom and forms liquid accumulation [6].

Correlation and mechanical method are used to predict the occurence of liquid loading in natural gas well [7]. Turner correlation is used to analyse the occurence of liquid loading in natural gas well as in (1) and can be converted into critical rate as in (2). 


$$
\begin{aligned}
& v_{t}=17.6 \frac{\sigma_{L}^{1 / 4}\left(\rho_{L}-\rho_{G}\right)^{1 / 4}}{\rho_{G}^{1 / 2}} \\
& q_{c r}=\frac{3.067 P v_{c r} A}{(T+460) z}
\end{aligned}
$$

The surface area of production pipe is also calculated by using (3).

$$
A=1 / 4 \frac{\pi I D_{\text {pipe }}^{2}}{144}
$$

Liquid loading doesn't occur directly in gas well, but sequently. Started with the initial condition where gas can flow well until liquid is accumulated in bottom hole due to depleted reservoir pressure [8].

\section{Chemical Injection Effectiveness}

In injecting chemical into well bottom, some factors influence the effectiveness of it. It must be considered to get the most effective result. Those factors are chemical type, chemical concentration, formation water salinity, reservoir temperature, and reservoir pressure.

- Chemical Type. It influences the stability of injected chemical. Due to polar characteristic of accumulated water, anionic chemical is the most effective to be injected because it can react well with accumulated water.

- Chemical Concentration. In injecting chemical into well bottom, chemical concentration has important rule to the effectiveness of chemical reaction with accumulated water. Well reaction between proper chemical with accumulated water will effectively decrease the liquid surface tension and overcome liquid loading more effectively. Practically, chemical concentration is also used to determine the chemical volume that will be injected into well bottom.

- Formation Water Salinity. Formation water is produced from reservoir with particular salinity. Liquid that is accumulated in well bottom is often formation water. Its salinity influence the stability of chemical that reacts. Higher formation water salinity decreases the stability of injected chemical. It because high salinity decreases critical miscelle concentration of the injected chemical. In high formation water salinity, chemical is not stable. It decreases the effectiveness of chemical injection.

- Reservoir Temperature. Too high reservoir temperature influence the stability of injected chemical. Therefore, the determination of chemical injection method must consider the reservoir temperature.

- Reservoir Pressure. Pressure highly influences the stability of injected chemical. Therefore, the determination of chemical injection method must consider the reservoir pressure.

\section{Chemical Component}

To overcome liquid loading in $\mathrm{X}$ well, chemical injection is used. This method is more efficient than mechanical method. Chemical, which is liquid consisted of ethoxy sulphate, alkane sulphonate, and petroleum sulphonate can effectively decrease liquid surface tension. Refers to Turner correlation, decreasing surface tension can cause critical rate decrease. If critical rate is lower than natural gas production rate, gas will easily flow from well bottom to surface. The injection of chemical mixture is applied due to some advantages that can be obtained, such as :

- chemical injection is simple and cheap,

- chemical injection can be applied with no complex downhole equipment,

- chemical injection in a very low gas rate well is applicable.

The mixture of ethoxy sulphate, alkane sulphonate, and petroleum sulphonate can alter liquid into bubble film that decreases density and surface tension. It decreases critical velocity. This mixture is reactive to polar molecule. Since that, it can react effectively with accumulated water to form foam.

The volume of injected chemical is related to the volume of accumulated water in well bottom and chemical concentration as in (4).

$$
V_{\text {chem }}=C_{\text {chem }} \times V_{\text {liq }}
$$

$\mathrm{V}_{\text {liq }}$ refers to volume of accumulated water in well bottom. It can be calculated using (5).

$$
\begin{aligned}
& V_{\text {liq }}=0.0492 \pi\left[I D_{\text {casing }}^{2}(D-E O P)-\right. \\
& \left.O D_{\text {tubing }}^{2} \quad(E O T-E O P)+I D_{\text {tubing }}^{2}(E O T+h-D)\right]
\end{aligned}
$$

Gas critical rate is calculated by determining surface tension and liquid density using (6) before and after chemical injection.

$$
\sigma=\left[P \sum_{i}^{n} \frac{\rho_{i}}{M w_{i}}\right]^{4}
$$

$\mathrm{P}$ is is an emphirical constant that is related to molecular volume of natural gas. Produced gas composition is obtained from chromatograph test, while molecular weight and parachor constant of each component is obtained from software simulation. Hydrocarbon and non-hydrocarbon component is mixed with chemical component (pseudo component) after injection process. 


\section{Chemical Injection in X Well}

\subsection{Chemical Volume}

Ethoxy sulphate, alkane sulphonate, and petroleum sulphonate is injected into $\mathrm{X}$ well with liquid loading. This volume of accumulated water is calculated to determine the volume and composition of chemical that will be injected into $\mathrm{X}$ well.

Table 1. Volume of Water Accumulation

\begin{tabular}{|l|c|c|}
\hline \multicolumn{1}{|c|}{ Parameter } & Value & Unit \\
\hline Casing diameter & 9.6 & $\mathrm{in}$ \\
\hline Well depth & 2017 & $\mathrm{ft}$ \\
\hline End of Packer depth & 1,673 & $\mathrm{ft}$ \\
\hline Tubing diameter & 2.5 & $\mathrm{in}$ \\
\hline End of Tubing depth & 1,706 & $\mathrm{ft}$ \\
\hline Height of column & 185 & $\mathrm{ft}$ \\
\hline \multirow{2}{*}{ Volume of Water Accumulation } & 3,089 & liter \\
\cline { 2 - 3 } & 19.4 & $\mathrm{bbl}$ \\
\hline
\end{tabular}

Based on Table 1, accumulated water in X well is 19.4 bbls. With $2 \%$ of chemical concentration, chemical volume is 0.4 bbls (61.7 liter).

\subsection{Chemical Composition}

The volume of accumulated water in X well is 19.4 bbls. It indicates that the small amount of accumulated water can highly influence the natural gas production rate. Due to that, chemical injection that consist of ethoxy sulphate, alkane sulphonate, and petroleum sulphonate is needed to overcome liquid loading. The proper amount and comparison of each component is a must to yield the most effective result. The mistake of chemical composition determination will cause more accumulated liquid in well bottom, not only water but also injected chemical itself. Therefore, chemical composition of each component is determined properly.

Accumulated water in well bottom is used to calculate the minimum volume of injected chemical. The injected chemical will mix with accumulated water in well bottom. Therefore, the volume of accumulated water is used as the bulk volume to determine chemical volume by using $2 \%$ of chemical concentration. The calculation result concludes that 0.4 bbls of chemical is needed. This volume is then converted to calculate the amount of each chemical component. It is related to the density of each chemical component. The density of ethoxy sulphate, alkane sulphonate, and petroleum sulphonate is $1.5 \mathrm{~g} / \mathrm{ml}, 0.124 \mathrm{~g} / \mathrm{ml}$, and $0.376 \mathrm{~g} / \mathrm{ml}$ respectively. Therefore, the mass of ethoxy sulphate, alkane sulphonate, and petroleum sulphonate in the chemical mixture is $92.53 \mathrm{~g}, 7.65 \mathrm{~g}$, and $23.19 \mathrm{~g}$ respectively.

\subsection{Gas Production After Chemical Injection}

Chemical injection decreases surface tension and allows gas to flow more effective. The condition at which critical rate is lower than gas rate allows gas to flow effectively from well bottom to surface. After chemical injection process is done, surface tension can be calculated.

By inputing parachor and molecular weight of each component into (6), surface tension of accumulated water after chemical injection is obtained $31 \mathrm{dyne} / \mathrm{cm}$. It is lower than that before chemical injection, which is 60 dyne $/ \mathrm{cm}$. It shows that chemical injection effectively decreases surface tension of accumulated liquid in bottom hole. After obtaining new surface tension, new gas critical rate after chemical injection can be obtained by using (1), (2), and (3). The surface tension decreases from 60 dyne/cm to $31 \mathrm{dyne} / \mathrm{cm}$ (47\%), while gas critical rate decreases from $1.28 \mathrm{MMScfd}$ to $1.08 \mathrm{MMScfd}$ $(15.6 \%)$.

Table 2. Increased Production of Natural Gas

\begin{tabular}{|l|c|c|c|c|}
\hline Conditions & $\begin{array}{c}\text { NG Prod. } \\
\text { (MMScfd) }\end{array}$ & $\begin{array}{c}\text { Liquid } \\
\text { Prod. } \\
\text { (Bpd) }\end{array}$ & $\begin{array}{c}\text { Critical } \\
\text { Vel. } \\
\text { (ft/s) }\end{array}$ & $\begin{array}{c}\text { Critical } \\
\text { rate } \\
\text { (MMScfd) }\end{array}$ \\
\hline $\begin{array}{l}\text { Before } \\
\text { Injection }\end{array}$ & 1.19 & 90 & 21.4 & 1.28 \\
\hline $\begin{array}{l}\text { After } \\
\text { Injection }\end{array}$ & 1.87 & 200 & 18.2 & 1.08 \\
\hline
\end{tabular}

Decreasing surface tension and gas critical rate increases gas production from $\mathrm{X}$ well. Production test is applied in 14 days ( 2 weeks) to get gas production profile after chemical injection into $\mathrm{X}$ well. Gas production from $\mathrm{X}$ well increases after chemical injection from 1.19 MMScfd to 1.87 MMScfd (57\%) as shown by Table 2 . Liquid production also increases. In the early of production test, which is day- 1 to day- 8 after chemical injection, gas production increases slowly and stable at day-9 to day-14. It shows that injected chemical needs particular time to react effectively with accumulated liquid in bottom hole. After the reaction is complete, gas increased production is stable. The increased gas production is then monetized with gas price which is determined by regulator taking into account the interests of the government [9].

\section{Conclusion}

Chemical injection into $\mathrm{X}$ well is effective to overcome liquid loading. With particular volume and concentration of chemical and water mixture that is adjusted with accumulated liquid volume, chemical injection can decrease surface tension and gas critical rate. New critical rate is lower than gas rate, that gas can effectively flow from well bottom to surface.

We express our gratitude to the Universitas Indonesia which has funded this research through the scheme of Hibah Publikasi 
Internasional Terindeks untuk Tugas Akhir Mahasiswa (PITTA) No. 2359/UN2.R3.1/HKP.05.00/2018.

\section{References}

1. Fitriani, I., Anindhita, Wahid, L. M. A., Sugiyono, A., and Adiarso. Indonesia Energy Outlook 2017: Clean Energy Technology Development Inisiative. Agency for the Assesment and Application of Technology (BPPT). 2017.

2. Guo, B., Lyons, W.C., \& Ghalambor, A, "Petroleum Production Engineering - A Computer Assisted Approach," Elsevier Science \& Technology Books, 2007.

3. Sajjad, F.M. \& Sukarno, P., "Optimasi Produksi Lapangan Gas Kering PSF dengan Mempertimbangkan Liquid Loading," Perpustakaan Digital ITB, 2010.

4. Binli, O. "Overview of Solutions to Prevent Liquid Loading Problems in Gas Wells". Master Thesis: The Graduate School of Natural and Applied Sciences of Middle East Technical University. 2009

5. Ardianto, E.S. \& Mucharam, L., "Analisa Aliran Dua Fasa pada Desain Penanggulangan Liquid Loading dengan Menggunakan Small Tube," Perpustakaan Digital ITB, 2013.

6. Passucci, C. \& Pelucchi, I.M., "Downhole Injection of Foaming Agents with Capillary String in A Mediterranian Offshore Gas Well," Paper presented at The 10th Offshore Mediterranian Conference \& Exhibition, March 2011.

7. Fu, W., "Gas Well Liquid Loading Onset and Plunger Lift Modeling," The University of Tulsa, The Graduate School, 2016.

8. Lea, J.F., Nickens, H.V., \& Wells, M., "Gas Well Deliquification," Elsevier Press, 2003.

9. Bawono, A.A \& Kusrini, E., "The Impact of Financing Investment Scenarios on Piped-Natural Gas Prices (GPs) for Household in Indonesia," International Journal of Technology, 2017. 